San Jose State University

SJSU ScholarWorks

Master's Theses

Master's Theses and Graduate Research

1997

\title{
Evaluation of the KSC-25 paste diet for rodents over multiple generations
}

John David Gossett

San Jose State University

Follow this and additional works at: https://scholarworks.sjsu.edu/etd_theses

\section{Recommended Citation}

Gossett, John David, "Evaluation of the KSC-25 paste diet for rodents over multiple generations" (1997). Master's Theses. 1499.

DOI: https://doi.org/10.31979/etd.wkhk-qux3

https://scholarworks.sjsu.edu/etd_theses/1499

This Thesis is brought to you for free and open access by the Master's Theses and Graduate Research at SJSU ScholarWorks. It has been accepted for inclusion in Master's Theses by an authorized administrator of SJSU ScholarWorks. For more information, please contact scholarworks@sjsu.edu. 


\section{INFORMATION TO USERS}

This manuscript has been reproduced from the microfilm master. UMI films the text directly from the original or copy submitted. Thus, some thesis and dissertation copies are in typewriter face, while others may be from any type of computer printer.

The quality of this reproduction is dependent upon the quality of the copy submitted. Broken or indistinct print, colored or poor quality illustrations and photographs, print bleedthrough, substandard margins, and improper alignment can adversely affect reproduction.

In the unlikely event that the author did not send UMI a complete manuscript and there are missing pages, these will be noted. Also, if unauthorized copyright material had to be removed, a note will indicate the deletion.

Oversize materials (e.g., maps, drawings, charts) are reproduced by sectioning the original, beginning at the upper left-hand corner and continuing from left to right in equal sections with small overlaps. Each original is also photographed in one exposure and is included in reduced form at the back of the book.

Photographs included in the original manuscript have been reproduced xerographically in this copy. Higher quality 6" $\times 9$ " black and white photographic prints are available for any photographs or illustrations appearing in this copy for an additional charge. Contact UMI directly to order.

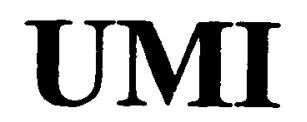

A Bell \& Howell Information Company 300 North Zeeb Road, Ann Arbor MI 48106-1346 USA

$313 / 761-4700 \quad 800 / 521-0600$ 



\title{
EVALUATION OF THE KSC-25 PASTE DIET FOR RODENTS OVER MULTIPLE GENERATIONS
}

\author{
A Thesis \\ Presented to \\ The Faculty of the Department of Biological Sciences \\ San Jose State University \\ In Partial Fulfillment \\ of the Requirements for the Degree \\ Master of Science
}

by

John David Gossett

August 1997 
OMI Number: 1386200

UMI Microform 1386200

Copyright 1997, by UMI Company. All rights reserved.

This microform edition is protected against unauthorized copying under Title 17, United States Code.

\author{
UMI \\ 300 North Zeeb Road \\ Ann Arbor, MI 48103
}


c) 1997

John David Gossett

ALL RIGHTS RESERVED 
APPROVED FOR THE DEPARTMENT OF BIOLOGICAL SCIENCES
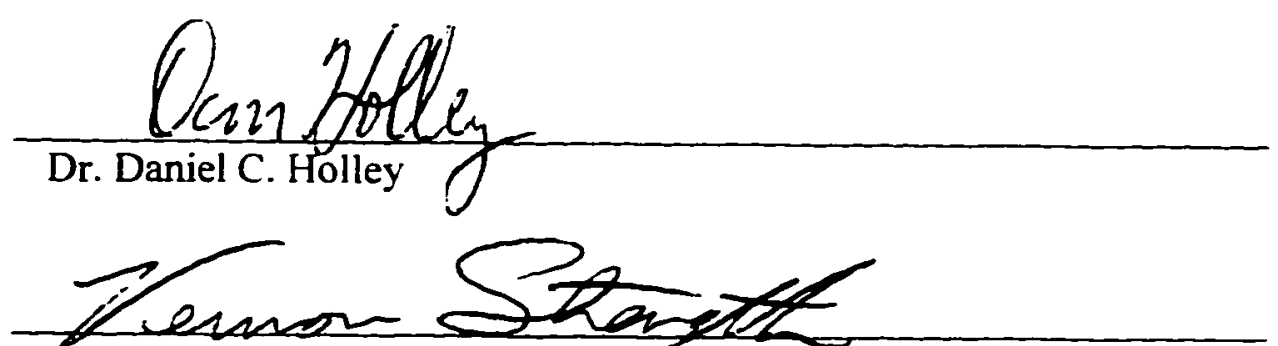

Dr. Vernon E. Strength, McDonnell Douglas Aerospace

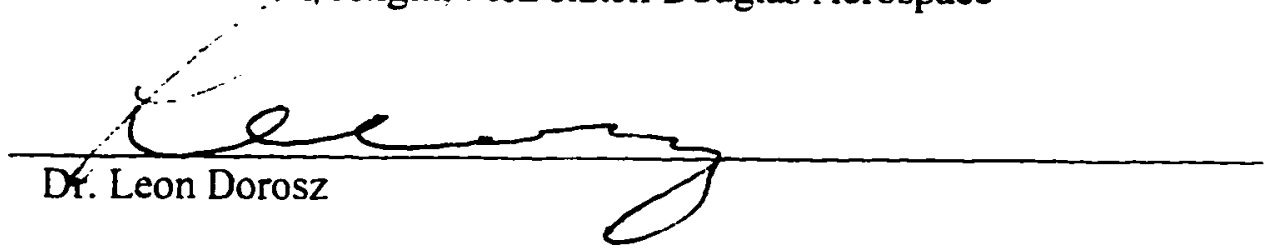

APPROVED FOR THE UNIVERSITY

Serena It then ger 


\section{ABSTRACT \\ EVALUATION OF THE KSC-25 PASTE DIET FOR RODENTS OVER MULTIPLE GENERATIONS \\ by John David Gossett}

The purpose of this research is to assess the adequacy of KSC -25 paste diet for experiments lasting many months and spanning several generations.

Eighteen female and 18 male rats were divided into three groups: control. paste diet with no water. and paste diet with ad libitum supplemental water. Each rat was mated to another in the same group. Rats from that generation $\left(F_{1}\right)$ were then mated. allowed to give birth $\left(F_{2 a}\right)$. and mated a second time after their first litter to produce a second litter $\left(F_{2 b}\right)$. Body weight. eviscerated carcass weight. selected organ weights. and selected blood parameters were measured for each generation.

Second generation reproductive efficiency (determined by number of litters in diet group. number of pups in litter. and weight of pups) was decreased in both paste groups compared to the control group. This indicates that the KSC-25 paste diet is not adequate for multigenerational breeding requirements. 


\section{ACKNOWLEDGMENTS}

The author wishes to express sincere appreciation to Dr. Daniel C. Holley (San Jose State University) for guidance, support. and friendship throughout the project. and to Dr. Vernon E. Strength (McDonnell Douglas Aerospace) for providing the funding and opportunity to pursue this research. Also. special thanks to Leon Dorosz. Ph.D.. from San Jose State University. Dennis Bernard and Joe Knapka. Ph.D.. from the NIH. and August Battles. Ph.D., from State University of New York. Albany for reviewing earlier manuscripts and helpful comments on data interpretation.

Also. a special thanks to the following San Jose State University support staff: Linda Goff. Jesse Martinez. and Carleen Mumaw. Finally. a very special thanks to the San Jose State University students who provided excellent technical support throughout this research effort: John Hughes. Mike Laidlaw. Kathrin Lammers. Elham Louis. Ted Lindstrom. Pedram Malek. Gary Mele. Sujata Naidu. Minaj Naeimi. Farhad Naji. Sharon Ngo. Greg Nguyen. Lawrence Nguyen. Theresa Nguyen. Tom Nguyen. Nathan Norris. Reza Riahi. Sherry Sami. Julie Sasur. Adam Seddiqui. Armen Shamamian. Aika Shepard. Kevin Soltani. Brian Quast. and Jeff Quast. 
TABLE OF CONTENTS

Page

ABSTRACT iv

ACKNOWLEDGMENTS $\quad v$

LIST OF TABLES vii

LIST OF TABLES (Continued) viii

LIST OF FIGURES ix

INTRODUCTION

METHODS 3

$\begin{array}{lc}\text { RESULTS } & 6\end{array}$

DISCUSSION 24

$\begin{array}{lr}\text { REFERENCES } & 30\end{array}$ 


\section{LIST OF TABLES}

Table 1. KSC -25 diet formulation.

Table 2. Parent generation 24 day pre-breeding weight gain. food consumption. caloric intake. and feed efficiency means and standard deviations.

$\begin{array}{lll}\text { Table } 3 . & \text { Estrous cycle activity of parent generation. } & 8\end{array}$

Table 4. Breeding results for parent generation female rats in each diet group. 9

Table 5. Mean number and culling weight ( \pm standard deviation) of pups born to parent generation.

Table 6. Male parent generation body weight, organ weights (grams). and blood measures.

Table 7. Female parent generation body weight. organ weights (grams). and blood measures.

Table 8. Male parent generation organ weight as percentage of total body weight and standard deviation.

Table 9. Female parent generation organ weight as percentage of total body weight and standard deviation.

Table 10. $\quad F_{1}$ generation 24 day pre-breeding weight gain. food consumption. caloric intake. and feed efficiency means and standard deviations.

Table 11. Estrus cycle activity of $F_{1}$ generation for first mating.

Table 12. Breeding results for $F_{I}$ generation (first mating) female rats in each diet group.

Table 13. Mean number and culling weight of pups born to $F_{1}$ generation first mating.

Table 14. Estrus cycle activity of $F_{1}$ generation for second mating. 


\section{LIST OF TABLES (Continued)}

Table 15. Breeding results for $F_{1}$ generation (second mating) female rats in each diet group.

Page

Table 16. Mean number and culling weight of pups born to $F_{1}$ generation second mating

Table 17. Male $F_{1}$ generation organ weights as percentage of total body weight and mean blood values with standard deviations.

Table 18. Female $F_{1}$ generation organ weights as percentage of total body weight and mean blood values with standard deviations. 


\section{LIST OF FIGURES}

Figure 1. Mean total water consumption and standard deviation over 24 day

Page pre-breeding period for parent generation males and females.

Figure 2. Mean total water consumption and standard deviation over 24 day pre-breeding period for $F_{1}$ generation males and females. 


\section{Introduction}

The Russian space biology effort has made extensive use of purified diets. A purified diet is one that is not based on cereal and/or animal meals as a major carbohydrate or protein source $(1,2.3)$. One of the earliest uses of paste diets (a purified diet combined with water that provides all nutritional and water needs) in a microgravity application was on the Soviet Cosmos missions (4). In 1973. the American Institute of Nutrition (AIN) created an ad hoc committee to provide guidelines on purified diets for U.S. researchers who had limited experience in experimental nutrition and to formulate a nutritionally adequate purified diet that could be used in standardized studies (5). The result of these deliberations was the creation of the AIN-76 purified diet. Since the original AIN committee meeting. many other modifications have been adopted and thus the creation of the improved AIN-76A and AIN-93 diets (5.6).

Based on recommendations from the earlier guidelines. the $\mathrm{KSC}-25$ paste diet (Table 1) was developed. This diet has a formulation similar to the AIN-76A diet with the addition of tapioca starch. instant cleargel. gelatin. and wheat gluten as components that would retain large quantities of water and bind the mixture (7). The KSC-25 diet formulation combined with water (66\% water to $34 \%$ diet by weight) results in a pastelike consistency.

Original evaluation of the KSC-25 paste diet by Battles. et al. determined the nutritional capability of the diet for growth of rats from age 35-63 days (7.8). The diet was formulated after the AIN-76A with some modifications to diet components to help 
Table 1. KSC-25 diet formulation Ingredients

Cornstarch

Percent by weight

Corn oil

51.2

Casein

7.0

Tapioca starch

10.5

Wheat gluten

9.1

Gelatin

5.0

Alphacel

5.0

AIN-76 Mineral Mix

3.5

Instant Cleargel

3.5

AIN-76 Vitamin Mix

3.0

Methionine

1.5

Choline bitartrate

0.5

0.2

TOTAL 100.0

absorb and retain water. The diet was assessed for nutritional adequacy as well as water content. The 28-day Battles` study using 48 Sprague-Dawley rats showed that there were no differences in growth and development between the KSC-25 paste diet rats (with and without supplemental water) and the control diet rats fed the AIN-76A diet plus water. Also. that study concluded that use of the supplemental water with KSC-25 paste diet was not necessary. However. when this diet was used for breeding by the Battles group. supplemental water was provided ad libitum. In addition. a preliminary study (D. C. Holley, N. Norris, and V. E. Strength. unpublished) found that adult females maintained on the KSC-25 paste diet retained normal estrous cycling.

The purpose of the current study is to determine whether rats fed KSC-25 paste diet have similar reproductive performance over two generations compared to rats fed standard rodent chow. This project is part of a program to develop a hardware delivery system for feeding paste diet to laboratory rodents and other specimen during space flight 
missions (McDonnell-Douglas Aerospace. Huntington Beach. CA). A parallel study addressed the issue of incisor development of rats maintained chronically on the KSC -25 paste diet (9).

\section{Material and Methods}

Thirty-six Sprague-Dawley rats ( 18 males and 18 females. 42 days of age) from Simonsen Laboratories (Gilroy. CA) were randomly distributed into three diet groups. each housed individually in single capacity shoe box cages ( 8.5 inches length $\times 7.75$ inches width $\times 7.75$ inches height). The temperature in the vivarium was $71 \pm 2^{\circ} \mathrm{F}$ (mean \pm S.D.) with a humidity of $50 \pm 11 \%$ (mean \pm S.D.) and a 12/12-hour light/dark cycle using fluorescent lighting (mean light intensity was 95.9 with standard deviation of 19.2 lux). The rats were given deionized water and the Control rodent chow (Harlan Teklad. Madison. WI) ad libitum during the three day control period.

The KSC-25 diet (supplied by ICN Biomedical. Cleveland. $\mathrm{OH}$ ) was mixed with deionized water using aseptic techniques so the mixture had $66 \%$ water (w/w\%). The paste diet was prepared twice a week and stored at $40^{\circ} \mathrm{F}$ in a covered container. Paste aliquots were poured into $6 \mathrm{oz}$. glass jars $(2.5 \times 3$ inches $)$.

The three diet groups consisted of two KSC -25 paste diet groups and one standard rodent lab chow group. all fed ad libitum. The first group. KSC-Paste. was fed the KSC$25 \mathrm{diet}(3.95 \mathrm{kcal} / \mathrm{gram})$ with $66 \%$ water with no supplemental water source. The second group. KSC-Paste + Water, received the KSC-25 diet hydrated to $66 \%$ and also had 
supplemental deionized water ad libitum. The third group. Control, was fed a standard rodent lab chow. Teklad rodent chow \#5863 (4.4 kcal/gram). with supplemental deionized water ad libitum. All diet groups consisted of 12 rats, 6 male and 6 female.

The rats were started on the respective test diets at 45 days of age. Daily visual observations were made of general animal health: food and water consumption were measured daily. and rat body weight measurements were taken every three days. At 57 days of age estrous cycle activity was monitored for 10 days by exfolative cytology of daily vaginal smears (cotton swab method). Smears were scored as one of the following: proestrus. estrus. metestrus. or diestrus (10). Males and females within the same diet group were paired and moved to standard sized shoe box cages for mating at 70 days old (to avoid delayed individual sexual competence) and allowed to mate for 8 days (11). Positive matings were determined by presence of a vaginal sperm plug(s). At the end of the mating period. males and females were separated. Females that did not become pregnant by 10 days were re-mated with proven males from the same diet group.

After females gave birth. pup numbers were recorded. Pup weights were obtained at five days of age and the litters culled to 4 male and 4 females per nursing dam. The pups were selected by removing the lightest pup for each sex. then removing the heaviest pup. then the lightest pup. etc.. until 4 males and 4 females remained. At 20 days of age the pups were removed from the mother and maintained on the same diet as their parents. The parent generation was anesthetized with $100 \%$ carbon dioxide. blood was removed via heart puncture. and then the rats euthanized with additional carbon dioxide. Blood 
parameters measured were hematocrit. hemoglobin, red blood cell count $(R B C)$, white blood cell count (WBC), and white blood cell differential count (performed by Veterinary Stat Service. Campbell. CA). Dissection weight measurements were total body weight. adrenals. heart. thymus. spleen. kidneys. gonads. skin. and eviscerated carcass. All organs. including the stomach. were examined for gross pathological differences during necropsy.

At pup age 33 days. a male and female were randomly selected to replace the male and female who parented the litter. These $F_{1}$ rats had food. water consumption and weight measurements taken in the same manner as the parent generation. The $F_{1}$ generation was mated with non-siblings of the same diet group according to the same procedures as the parent generation. and allowed to give vaginal birth to the $F_{2}$ generation and nurse the pups to 20 days of age. Pups from these litters were counted and weighed at day 6 and then weighed every three days. At day 20. the pups were weighed and weaned from their mothers and removed from the experiment. In order to provide a reproductive stress. the females were then re-mated 5 days after litter removal to produce a second $F_{2}$ litter. The pups from this second $F_{2}$ litter were treated the same as the first $F_{2}$ litter. At the end of the 20 day nursing period. males and females were dissected in the same manner as the parent generation.

Unless otherwise mentioned. data is presented as mean \pm standard deviation (SD). One-way analysis of variance (ANOVA) with Tukey`s post hoc or ANOVA on ranks (Kruskal-Wallis) with Dunn`s method were performed to determine significant 
differences between groups with the exception of the estrous cycling activity which was analyzed with a $G$ statistic contingency table analysis (12). The Alpha level was set at 0.05 ( $95 \%$ confidence interval) for all statistical analyses and ANOVAs were performed using SigmaStat v2.02 (Jandel Scientific. San Rafael. CA).

This study was approved by the San Jose State University Institutional Animal Care and Use Committee.

\section{Results}

Adult rats in all groups appeared healthy in all generations throughout the study. The parent generation weight gain. food consumption. caloric intake and feed efficiency are shown in Table 2. The dry food equivalent weight for both of the KSC-25 diets was calculated by multiplying total KSC -25 paste weight consumed by 0.34 . All rats gained similar amounts of weight during this period. but the Control diet rats consumed more dry weight of food $(p<0.05)$ and consequently more calories $(p<0.001)$ than the KSC-Paste and KSC-Paste + Water groups for both males and females. A caloric value of 3.95 $\mathrm{kcal} / \mathrm{gram}$ for the KSC-25 diet was calculated as the average of four values from a proximate assay performed by the manufacturer. ICN Biomedicals. This value differs from their estimated $3.79 \mathrm{kcal} / \mathrm{gram}$ reported in the product information sheet. The 3.95 $\mathrm{kcal} / \mathrm{gram}$ value is closer to the earlier calculation of $4.26 \mathrm{kcal} / \mathrm{gram}$ found by Battles (8). Feed efficiency was calculated by amount of weight gain divided by amount of food consumed $\times 100$. In the males. this resulted in a higher feed efficiency of $27.1 \pm 2.1 \%$ in 
Table 2. Parent generation 24 day pre-breeding weight gain. food consumption. caloric intake. and feed efficiency means and standard deviations. There were 6 males and 6 females in each group.

\begin{tabular}{|c|c|c|c|c|}
\hline Male values & KSC-Paste & $\begin{array}{c}\text { KSC-Paste + } \\
\text { Water }\end{array}$ & Control & p \\
\hline Mean body weight on day I & $181.3 \pm 5.2$ & $181.0 \pm 7.5$ & $181.0 \pm 6.1$ & 0.994 \\
\hline $\begin{array}{l}\text { Pre-breeding weight gain (grams) } \\
\% \text { pre-breeding weight gain (grams) } \\
\text { Total food consumption (grams) } \\
\text { Caloric intake (kcal) } \\
\text { Pre-breeding feed efficiency } \\
\text { (wt. gained/food consumed) } \times 100\end{array}$ & $\begin{array}{c}138.3 \pm 17.4 \\
76.2 \pm 8.4 \\
505.9 \pm 43.7^{\mathrm{a}} \\
1998.4 \pm 172.8^{\mathrm{a}} \\
27.1 \pm 2.1^{\mathrm{a}}\end{array}$ & $\begin{array}{c}133.5 \pm 16.3 \\
74.0 \pm 10.5 \\
519.1 \pm 40.5^{\mathrm{a}} \\
2050.5 \pm 160.0^{\mathrm{a}} \\
25.7 \pm 2.3^{2}\end{array}$ & $\begin{array}{c}117.3 \pm 21.0 \\
64.8 \pm 11.4 \\
583.0 \pm 65.6^{\mathrm{b}} \\
2565.2 \pm 288.6^{\mathrm{b}} \\
20.0 \pm 1.4^{\mathrm{b}}\end{array}$ & $\begin{array}{l}0.150 \\
0.157 \\
0.043 \\
<0.001 \\
0.002 *\end{array}$ \\
\hline \multicolumn{5}{|l|}{ Female values } \\
\hline Mean body weight on day I & $153.7 \pm 3.6$ & $153.3 \pm 4.3$ & $153.5 \pm 4.2$ & 0.990 \\
\hline $\begin{array}{l}\text { Pre-breeding weight gain (grams) } \\
\% \text { pre-breeding weight gain (grams) } \\
\text { Total food consumption (grams) } \\
\text { Caloric intake (kcal) } \\
\text { Pre-breeding feed efficiency }\end{array}$ & $\begin{array}{c}57.2 \pm 6.5 \\
37.2 \pm 4.2 \\
398.0 \pm 18.9^{\mathrm{a}} \\
1572.0 \pm 74.6^{\mathrm{a}} \\
14.4 \pm 1.5^{\mathrm{ab}} \\
\end{array}$ & $\begin{array}{c}63.0 \pm 8.3 \\
41.1 \pm 5.2 \\
385.2 \pm 24.1^{\mathrm{a}} \\
1521.4 \pm 95.2^{\mathrm{a}} \\
16.4 \pm 1.9^{\mathrm{a}} \\
\end{array}$ & $\begin{array}{c}61.0 \pm 9.6 \\
39.8 \pm 6.3 \\
+64.8 \pm 24.1^{b} \\
2045.3 \pm 106.2^{b} \\
13.1 \pm 1.8^{b}\end{array}$ & $\begin{array}{c}0.476 \\
0.469 \\
<0.001 \\
<0.001 \\
0.020 \\
\end{array}$ \\
\hline
\end{tabular}

(wt. gained/food consumed) $\times 100$

* Indicates ANOVA on ranks (Kruskal-Wallis).

${ }^{a, b}$ Superscripts across a line with the same letter are not significantly different $(p>0.05)$.

the KSC-Paste and $25.7 \pm 2.3 \%$ in the KSC-Paste + Water groups versus the Control rat feed efficiency of $20.0 \pm 1.4 \%$. Female feed efficiencies between the KSC-Paste + Water and Control were $16.4+1.9 \%$ and $13.1+1.8 \%$ respectively.

Male water consumption (water consumption for the KSC-25 groups was calculated by total paste weight consumed over the pre-breeding period multiplied by $0.66)$ was significantly higher in the two KSC -25 paste groups $(p<0.001)$. as is shown in Figure 1. with the KSC-Paste rats averaging $987 \pm 76 \mathrm{ml}$ and the KSC-Paste + Water averaging $1.115 \pm 113 \mathrm{ml}$ compared to the Control group drinking $724 \pm 99 \mathrm{ml}$. The females ${ }^{\circ}$ water consumption pattern was similar to the males: KSC-Paste $772 \pm 37 \mathrm{ml}$. the KSC-Paste + Water $855 \pm 41 \mathrm{ml}$. and Control $698 \pm 56 \mathrm{ml}$ 


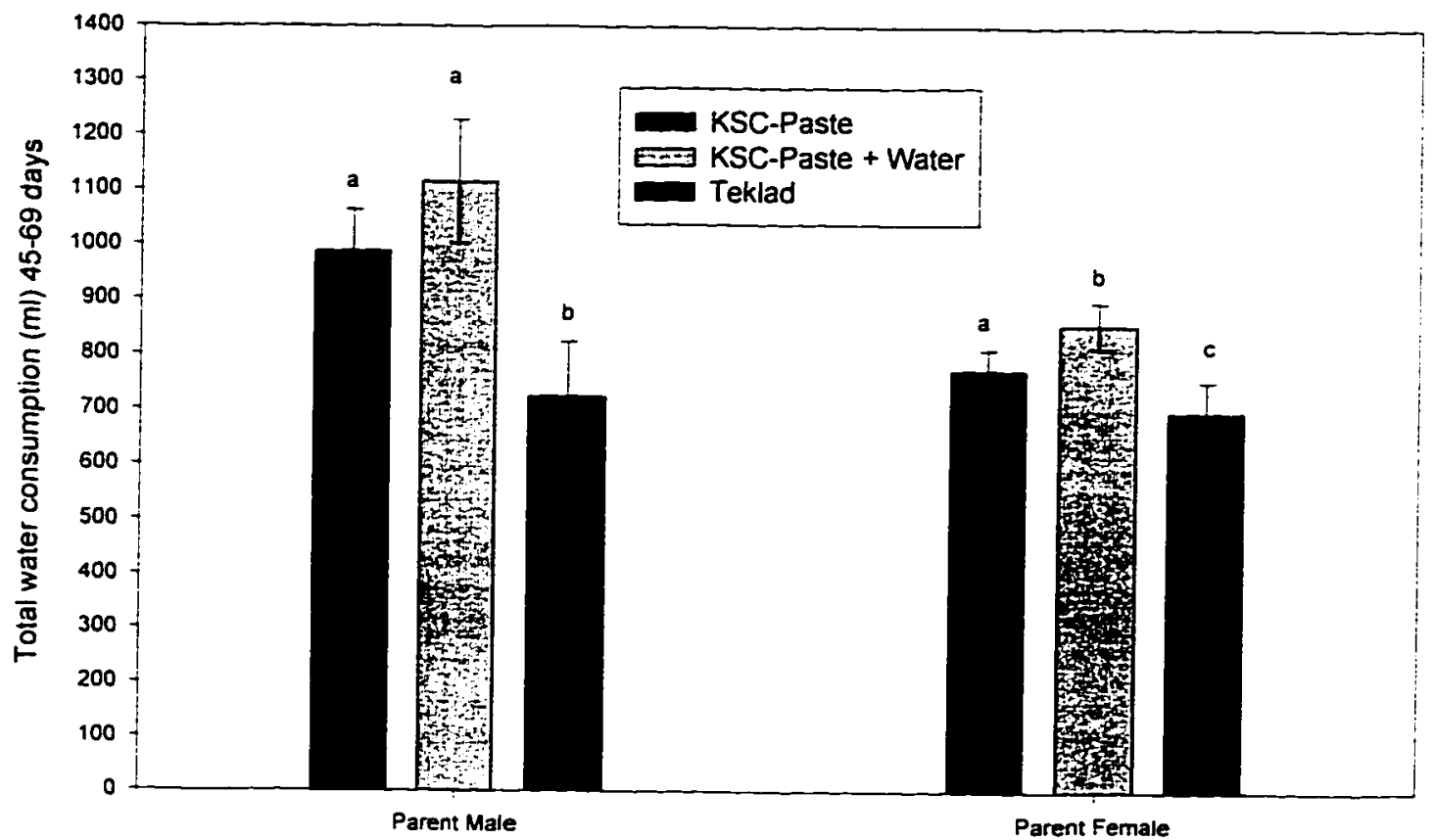

Figure 1. Mean total water consumption and standard deviation over 24 day pre-breeding period for parent generation males and females. $p<0.001$ for males and $p=0.002$ for females.

${ }^{2 b . c}$ Superscripts across a line with the same letter are not significantly different $(p>0.05)$.

Estrous cycling for all three parent generation diet groups is shown in Table 3.

There was not a significant difference $\left(\chi^{2}=1.744\right.$, and $\left.p>0.25\right)$ in the timing of estrous cycle stages between diet groups. but there was one female in both the KSC-Paste and KSC-Paste + Water groups that did not cycle during the test interval.

Table 3. Estrous cycle activity of parent generation $\left(\chi^{2}=1.744\right.$. and $\left.p>0.25\right)$.

\begin{tabular}{|l|c|c|c|}
\hline Group & KSC-Paste & KSC-Paste + Water & Control \\
\hline \hline $\mathrm{n}=$ & 6 & 6 & 6 \\
\hline Females cycling & 5 & 5 & 6 \\
\hline
\end{tabular}

The fertility data for the parent generation are summarized in Table 4. Both the KSC-Paste and KSC-Paste + Water only had two pregnancies result from the first mating attempt and both groups had three of the four females become pregnant in the re-mating 
attempt. There was not a significant difference $(p>0.25)$ in the number of litters produced in each diet group. There were no apparent pup reabsorptions (based on rapid weight gain post mating) for any of the females who did not become pregnant. For both the KSC-Paste and KSC-Paste + Water. three of the four females that did not become pregnant in the first mating did become pregnant in the second mating attempt by male breeders proven successful (males that produced litters with other females) in the first mating. In all groups. some females became pregnant even though there was no observation of sperm plugs. The female in the KSC-Paste group that did not become pregnant was not cycling. but was sperm plug positive. The KSC-Paste + Water femaie

Table 4. Breeding results for parent generation female rats in each diet group $\left(\chi^{2}=1.744\right.$, and $\left.p>0.25\right)$.

\begin{tabular}{|l|c|c|c|}
\hline & KSC-Paste & KSC-Paste + Water & Control \\
\hline \hline $\mathrm{n}=$ & 6 & 6 & 6 \\
\hline Births & $5^{*}$ & $5^{*}$ & 6 \\
\hline Births w/out sperm plug observed $^{2}$ & 2 & 3 & 2 \\
\hline Females with total reabsorptions $^{6}$ & 0 & 0 & 0 \\
\hline Females w/Sperm plug +. not pregnant & 1 & 1 & 0 \\
\hline Litters with dead pups/pups cannibalized $^{6}$ & 2 & 4 & 0 \\
\hline
\end{tabular}

Number of females that gave birth without detection of sperm plug.

${ }^{b}$ Number of females that were pregnant based on weight gain but did not give birth.

"Number of sperm plug positive females that did not become pregnant.

* Four of the six females were re-mated with proven breeders.

that did not become pregnant in the second mating attempt was cycling and sperm plug positive.

All of the Control females in the parent generation became pregnant and there was no observation of pup mortality or sign of pups being cannibalized. Both the KSC-Paste and KSC-Paste + Water groups had litters with dead pups or signs of pups being cannibalized. 
The resulting litters and culling weights are presented in Table 5. These

Table 5. Mean number and culling weight ( \pm standard deviation) of pups born to parent generation.

\begin{tabular}{|l|c|c|c|c|}
\hline & $\begin{array}{c}\text { KSC-paste } \\
\mathrm{n}=5\end{array}$ & $\begin{array}{c}\text { KSC-paste + water } \\
\mathrm{n}=5\end{array}$ & $\begin{array}{c}\text { Control } \\
\mathrm{n}=6\end{array}$ & $\mathrm{p}$ \\
\hline Mean \# pups & $12.4 \pm 3.0$ & $11.4 \pm 4.5$ & $13.5 \pm 2.3$ & 0.634 \\
\hline Mean cuiling weight $(\mathrm{g})$ & $10.7 \pm 2.9^{\mathrm{a}}$ & $10.6 \pm 2.3^{\mathrm{a}}$ & $11.5 \pm 1.3^{\mathrm{b}}$ & $0.001^{*}$ \\
\hline
\end{tabular}

* Indicates ANOVA on ranks (Kruskal-Wallis).

${ }^{\text {ab }}$ Superscripts across a line with the same letter are not significantly different $(p>0.05)$.

pregnancies resulted in no difference in the pup numbers between the KSC-Paste. KSC-

Paste + Water. and Control with 12.4 2 3.0. 11.4 \pm 4.5. and 13.5 \pm 2.3 pups. respectively.

There was a significant difference in the birth weights of pups from the KSC-Paste (10.7 $\pm 2.9 \mathrm{~g})$ and KSC-Paste + Water $(10.6 \pm 2.3 \mathrm{~g})$ compared to the Control pups (11.5 \pm 1.3 g).

The total body and organ weights for parent generation males are shown in Table 6. There was no difference in organ weights between the KSC-Paste and KSC-Paste + Water at $1.22 \pm 0.06 \mathrm{~g}$ compared to the KSC-Paste + Water of $1.08 \pm 0.11 \mathrm{~g}$ and the Control weight of $1.08 \pm 0.06 \mathrm{~g}$. Thymus mean weights between the KSC-Paste and Control diets were different. with the KSC-Paste weighing significantly more at $0.213 \pm$ $0.042 \mathrm{~g}$ compared to $0.143 \pm 0.029 \mathrm{~g}$. The KSC-Paste + Water diet was not statistically different from either group with a mean thymus weight of $0.192 \pm 0.053 \mathrm{~g}$. Female mean blood values. shown in Table 7. were the same between diet groups for RBC. WBC. and white blood cell differential counts including eosinophils. monocytes. basophils. and bands. The hematocrit of the two KSC-25 diet groups was significantly higher than the Control group. The KSC-Paste hematocrit was $50.5 \pm 2.3 \%$. the KSC-Paste + Water was 
Table 6. Male parent generation body weight. organ weights (grams). and blood measures. Values are mean $\pm S D$ ( $n=6$ for all groups).

\begin{tabular}{|c|c|c|c|c|}
\hline Mean Organ Wt. & KSC-Paste & KSC-Paste - Water & Control & $\mathbf{p}$ \\
\hline Total body wt. & $410.2 \pm 72.1$ & $344.5 \pm 67.4$ & $386.5 \pm 29.7$ & 0.188 \\
\hline Eviscerated carcass & $268.7 \pm 22.2^{\mathrm{a}}$ & $266.2 \pm 15.0^{2}$ & $233.1 \pm 19.2^{b}$ & 0.009 \\
\hline Skin & $79.1 \pm 11.6$ & $70.3 \pm 11.1$ & $68.2 \pm 7.9$ & 0.186 \\
\hline Adrenals & $0.031 \pm 0.006$ & $0.032 \pm 0.010$ & $0.026 \pm 0.005$ & 0.352 \\
\hline Heart & $1.41 \pm 0.15^{\mathrm{a}}$ & $1.33 \pm 0.07^{\mathrm{a}}$ & $1.20 \pm 0.09^{b}$ & 0.012 \\
\hline Thymus & $0.435 \pm 0.132$ & $0.442 \pm 0.123$ & $0.300 \pm 0.037$ & 0.060 \\
\hline Spleen & $1.14 \pm 0.92$ & $1.09 \pm 0.86$ & $0.71 \pm 0.08$ & $0.476^{*}$ \\
\hline Kidney & $3.06 \pm 0.27$ & $2.88 \pm 0.41$ & $2.83 \pm 0.47$ & 0.570 \\
\hline Testes & $3.17 \pm 0.84$ & $3.35 \pm 0.25$ & $3.40 \pm 0.21$ & 0.527 \\
\hline \multicolumn{5}{|l|}{ Mean blood values: } \\
\hline Hematocrit & $49.2 \pm 2.32$ & $46.0 \pm 3.95$ & $45.0 \pm 4.73$ & $0.074^{*}$ \\
\hline Hemoglobin & $13.9 \pm 1.50$ & $13.8 \pm 1.60$ & $13.2 \pm 1.28$ & 0.656 \\
\hline $\mathrm{RBC}$ & $8.86 \pm 1.01$ & $8.32 \pm 1.18$ & $7.78 \pm 1.55$ & 0.360 \\
\hline WBC & $9.85 \pm 2.53$ & $11.40 \pm 5.11$ & $9.63 \pm 4.47$ & 0.732 \\
\hline Neutrophils & $4.80 \pm 1.64$ & $5.40 \pm 3.21$ & $5.40 \pm 3.21$ & 0.926 \\
\hline Lympocytes & $94.6 \pm 2.3$ & $94.4 \pm 3.4$ & $94.2 \pm 3.7$ & 0.980 \\
\hline Eosinophils & $0.40 \pm 0.55$ & $0.40 \pm 0.55$ & $1.00 \pm 0.71$ & 0.235 \\
\hline Monocytes & 0 & 0 & 0 & \\
\hline Basophils & 0 & 0 & 0 & \\
\hline Bands & 0 & 0 & 0 & \\
\hline
\end{tabular}

$49.3 \pm 1.5 \%$ and the Control $45.8 \pm 2.5 \%$. Hemoglobin followed the same trend with the KSC-25 diets having higher concentrations $(14.8 \pm 0.5 \mathrm{~g} / \mathrm{dl}$ for the KSC-Paste and $15.2 \pm 0.6 \mathrm{~g} / \mathrm{dl}$ for KSC-Paste + Water $)$ than the Control diet $(13.4 \pm 0.8 \mathrm{~g} / \mathrm{dl})$. Percent neutrophils in the Control diet group $(30.67 \pm 8.14)$ was significantly higher than the KSC-Paste diet group $(10.83 \pm 7.71 \%)$. The KSC-Paste + Water diet group was not different from either group $(19.00 \pm 13.78 \%)$. The lymphocyte count for the KSC-Paste group was $88.5 \pm 7.7 \%$ which was significantly higher $(p<0.05)$ than the 
Table 7. Female parent generation total grams and standard deviations of body and organ weights and mean blood values with standard deviations ( $n=6$ for all groups).

\begin{tabular}{l|cccc} 
Mean Organ Wt. & KSC-Paste & KSC-Paste + Water & Control & $p$ \\
\hline Total body wt. & $312.7 \pm 25.0$ & $300.5 \pm 16.1$ & $312.2 \pm 19.0$ & 0.518 \\
Eviscerated Carcass & $179.2 \pm 16.5^{\mathrm{a}}$ & $176.4 \pm 17.5^{\mathrm{a}}$ & $146.2 \pm 9.3^{\mathrm{b}}$ & 0.003 \\
Skin & $64.5 \pm 17.5$ & $62.4 \pm 13.2$ & $72.5 \pm 6.4$ & 0.610 \\
& & & & \\
Adrenals & $0.036 \pm 0.013^{\mathrm{a}}$ & $0.035 \pm 0.012^{\mathrm{a}}$ & $0.056 \pm 0.009^{\mathrm{b}}$ & 0.008 \\
Heart & $1.22 \pm 0.06^{\mathrm{a}}$ & $1.08 \pm 0.11^{\mathrm{b}}$ & $1.08 \pm 0.06^{\mathrm{b}}$ & 0.012 \\
Thymus & $0.213 \pm 0.042^{\mathrm{a}}$ & $0.192 \pm 0.053^{\mathrm{ab}}$ & $0.143 \pm 0.029^{\mathrm{b}}$ & 0.034 \\
Spleen & $0.64 \pm 0.03$ & $0.60 \pm 0.08$ & $0.64 \pm 0.08$ & 0.447 \\
Kidney & $2.11 \pm 0.21$ & $2.04 \pm 0.12$ & $2.22 \pm 0.26$ & 0.331 \\
Ovaries & $0.15 \pm 0.02$ & $0.14 \pm 0.03$ & $0.13 \pm 0.02$ & 0.492 \\
& & & & \\
Mean blood values & & & & \\
\hline \hline Hematocrit & $50.5 \pm 2.3^{\mathrm{a}}$ & $49.3 \pm 1.5^{\mathrm{a}}$ & $45.8 \pm 2.5^{\mathrm{b}}$ & $0.005^{\mathrm{*}}$ \\
Hemoglobin & $14.8 \pm 0.5^{\mathrm{a}}$ & $15.2 \pm 0.6^{\mathrm{a}}$ & $13.4 \pm 0.8^{\mathrm{b}}$ & $<0.001$ \\
RBC & $9.21 \pm 0.55$ & $8.60 \pm 0.73$ & $8.17 \pm 0.86$ & 0.075 \\
WBC & $9.02 \pm 1.82$ & $10.29 \pm 2.96$ & $11.42 \pm 4.18$ & 0.437 \\
& & & & \\
Neutrophils & $10.83 \pm 7.71^{\mathrm{a}}$ & $19.00 \pm 13.78^{\mathrm{ab}}$ & $30.67 \pm 8.14^{\mathrm{b}}$ & 0.015 \\
Lympocytes & $88.5 \pm 7.7^{\mathrm{a}}$ & $79.8 \pm 13.3^{\mathrm{b}}$ & $68.7 \pm 8.6^{\mathrm{b}}$ & 0.014 \\
Eosinophils & $1.00 \pm 0.89$ & $1.33 \pm 0.82$ & $1.00 \pm 0.89$ & $0.831^{*}$ \\
Monocytes & $0.17 \pm 0.41$ & $0.33 \pm 0.52$ & 0 & $0.322^{*}$ \\
Basophils & 0 & 0 & 0 & \\
Bands & 0 & 0 & 0 & \\
\hline
\end{tabular}

- Units for hematocrit as \% hemoglobin as $\mathrm{g} / \mathrm{dl}$. red blood cell count as (RBC) $\times 10^{6 /} / \mathrm{mm}^{3}$. white blood cell count as $(\mathrm{WBC}) \times 10^{3} / \mathrm{mm}^{3}$. Differential white biood cells expressed in percent.

${ }^{\text {ab }}$ Superscripts across a line with the same letter are not significantly different $(p>0.05)$.

* Indicates ANOVA on ranks (Kruskal-Wallis).

KSC-Paste + Water group at $79.8 \pm 13.3 \%$ and the Control group at $68.7 \pm 8.6 \%$. Male organ weights as a percentage of the total body weight are presented in Table 8. All organ weights as a percentage of total body weight were not significantly different except the carcass and the thymus. The KSC-25-Paste + Water group mean carcasspercentage was $79.6 \pm 15.0$ and the Control group was $60.3 \pm 1.7 \%$ which were significantly different $(\mathrm{p}<0.005)$ from each other (the KSC-25-Paste group was not significantly different from either group with a mean percentage of $67.1 \pm 12.9$ ). The KSC-Paste + 
Water groups had a thymus percentage of $0.105 \pm 0.023$ which was significantly heavier $(p<0.05)$ compared to the Control group thymus percentage of $0.078 \pm 0.009$.

Table 8. Male parent generation organ weights as percentage of total body weight and standard deviation ( $n=6$ for all groups).

\begin{tabular}{l|ccccc} 
Mean Organ Wt. & KSC-Paste & KSC-Paste + Water & Control & $p$ \\
\hline \hline Eviscerated carcass & $67.1 \pm 12.9^{\mathrm{ab}}$ & $79.6 \pm 15.0^{\mathrm{a}}$ & $60.3 \pm 1.7^{\mathrm{b}}$ & $0.004^{*}$ \\
Skin & $19.8 \pm 4.9$ & $21.5 \pm 7.3$ & $17.7 \pm 1.8$ & $0.895^{*}$ \\
& & & & \\
Adrenals & $0.008 \pm 0.002$ & $0.010 \pm 0.005$ & $0.007 \pm 0.001$ & 0.242 \\
Heart & $0.35 \pm 0.06$ & $0.40 \pm 0.09$ & $0.31 \pm 0.02$ & $0.097^{*}$ \\
Thymus & $0.105 \pm 0.023^{\mathrm{ab}}$ & $0.136 \pm 0.058^{\mathrm{a}}$ & $0.078 \pm 0.009^{\mathrm{b}}$ & $0.036^{*}$ \\
Spleen & $0.28 \pm 0.21$ & $0.31 \pm 0.19$ & $0.18 \pm 0.01$ & $0.318^{*}$ \\
Kidney & $0.77 \pm 0.17$ & $0.87 \pm 0.26$ & $0.73 \pm 0.10$ & 0.448 \\
Testes & $0.80 \pm 0.26$ & $1.00 \pm 0.21$ & $0.88 \pm 0.04$ & 0.213 \\
\hline
\end{tabular}

${ }^{26}$ Superscripts across a line with the same letter are not significantly different $(p>0.05)$

* Indicates ANOVA on ranks (Kruskal-Wallis).

For comparison. organs from the male parent generation were compared as a percentage of eviscerated carcass weight (not shown). When analyzed in this fashion. all of the organs were similar except the testes $(\mathrm{p}<0.005)$. Both KSC -25 groups had smaller testes than the Control group.

Organs as a percentage of total body weight for females are shown in Table 9. There was not a significant difference in the heart. spleen. kidney. and ovaries percentages between the groups. The carcass mean percentage of the total body weight for the KSC-25-Paste group ( $57.5 \pm 6.0 \%)$ and KSC-25-Paste + Water group ( $58.9 \pm$ $3.6 \%)$ were significantly heavier $(p<0.005)$ than the Control group $(46.9 \pm 3.0 \%)$. Adrenal glands for the KSC-Paste and KSC-Paste + Water diets were significantly smaller (both at $0.012 \pm 0.004 \%$ ) than the Control diet adrenal percentage $(0.018 \pm$ 
0.004 ) with $p<0.05$. The KSC-Paste group mean thymus percentages. at $0.068 \pm 0.012 \%$. was significantly larger $(p<0.05)$ than the Control mean thymus of $0.046 \pm 0.009 \%$.

Table 9. Female parent generation organ weights as percentage of total body weight and standard deviation ( $n=6$ for all groups).

\begin{tabular}{l|ccccc} 
Mean Organ Wt. & KSC-Paste & KSC-Paste - Water & Control & $p$ \\
\hline \hline Eviscerated carcass & $57.5 \pm 6.0^{\mathrm{a}}$ & $58.9 \pm 3.6^{\mathrm{a}}$ & $46.9 \pm 3.0^{\mathrm{b}}$ & $<0.001$ \\
Skin & $20.5 \pm 4.5$ & $20.8 \pm 4.7$ & $23.2 \pm 0.9$ & $0.459^{*}$ \\
& & & & \\
Adrenals & $0.012 \pm 0.004^{\mathrm{a}}$ & $0.012 \pm 0.004^{\mathrm{a}}$ & $0.018 \pm 0.004^{\mathrm{b}}$ & $0.031^{*}$ \\
Heart & $0.39 \pm 0.05$ & $0.36 \pm 0.03$ & $0.35 \pm 0.02$ & 0.096 \\
Thymus & $0.068 \pm 0.012^{\mathrm{a}}$ & $0.064 \pm 0.016^{\mathrm{ab}}$ & $0.046 \pm 0.008^{\mathrm{b}}$ & 0.017 \\
Spleen & $0.21 \pm 0.02$ & $0.20 \pm 0.02$ & $0.21 \pm 0.02$ & 0.842 \\
Kidney & $0.68 \pm 0.10$ & $0.68 \pm 0.04$ & $0.71 \pm 0.06$ & 0.694 \\
Ovaries & $0.048 \pm 0.009$ & $0.046 \pm 0.009$ & $0.041 \pm 0.008$ & 0.483 \\
\hline
\end{tabular}

${ }^{a . b}$ Superscripts across a line with the same letter are not significantly different $(p>0.05)$

* Indicates ANOVA on ranks (Kruskal-Wallis).

When female parent generation organs are compared as a percentage of carcass weight (not shown), the adrenals. heart. spleen. kidneys. and skin all are significantly different among groups. With the exception of the heart. both KSC-25 organs mentioned above were different from the Control group (for the heart. the KSC-25-Paste + Water group was significantly different from the KSC-25-Paste and Control groups).

The male $F_{1}$ generation pre-breeding weight gain is shown in the Table 10. The mean body weight on day 1 represent rats that are 45 days old. All of these rats have been fed only the diet that their mothers were fed during the experiment. The mean weights were significantly different between the KSC-Paste and the Control diets. The KSCPaste body weights on day I were $194.5 \pm 11.8 \mathrm{~g}$ compared to the Control weights of $221.2 \pm 9.4 \mathrm{~g}$ (the KSC-Paste + Water weights were not different from either group). All males in the three groups had similar weight gain and percent weight gain. The Control 
diet group consumed significantly more $(p<0.001)$ dry weight of food eating $639.2 \pm 17.0$

g of chow than the KSC-Paste group. $528.3 \pm 44.5 \mathrm{~g}$, and the KSC-Paste + Water group.

Table 10. $F_{1}$ generation 24 day pre-breeding weight gain. food consumption, caloric intake, and feed efficiency means and standard deviations. Males and females shown with all weights in grams and feed efficiency in percent.

\begin{tabular}{|c|c|c|c|c|}
\hline $\begin{array}{r}\text { Male values } \\
\end{array}$ & $\begin{array}{c}\text { KSC-Paste } \\
n=6 \\
\end{array}$ & $\begin{array}{c}\text { KSC-Paste - Water. } \\
n=6\end{array}$ & $\begin{array}{c}\begin{array}{c}\text { Control } \\
n=5\end{array} \\
\end{array}$ & p \\
\hline Mean body weight on day I & $194.5 \pm 11.8^{3}$ & $206.0 \pm 15.2^{\mathrm{ab}}$ & $221.2 \pm 9.4^{b}$ & 0.012 \\
\hline $\begin{array}{l}\text { Pre-breeding weight gain } \\
\% \text { pre-breeding weight gain } \\
\text { Total food consumption (grams) } \\
\text { Caloric intake (kcal) } \\
\text { Pre-breeding feed efficiency } \\
\text { (wt. gained/food consumed) } \times 100\end{array}$ & $\begin{aligned} 145.0 & \pm 19.2 \\
74.7 & \pm 9.8 \\
528.3 & \pm 44.5^{\mathrm{a}} \\
2086.7 & \pm 175.8^{\mathrm{a}} \\
27.5 & \pm 3.5^{\mathrm{a}}\end{aligned}$ & $\begin{aligned} 143.8 & \pm 15.2 \\
70.1 & \pm 8.4 \\
536.0 & \pm 45.6^{\mathrm{a}} \\
2117.9 & \pm 180.0^{\mathrm{a}} \\
26.9 & \pm 2.5^{\mathrm{a}}\end{aligned}$ & $\begin{array}{c}138.4 \pm 8.1 \\
62.7 \pm 5.4 \\
639.2 \pm 17.0^{b} \\
2811.6 \pm 74.9^{b} \\
21.6 \pm 1.1^{b}\end{array}$ & $\begin{array}{c}0.758 \\
0.087 \\
<0.001 \\
<0.001 \\
0.004\end{array}$ \\
\hline \multicolumn{5}{|l|}{ Female values } \\
\hline Mean body weight on day 1 & $145.8 \pm 9.7$ & $159.0 \pm 12.3$ & $156.2 \pm 5.9$ & 0.086 \\
\hline $\begin{array}{l}\text { Pre-breeding weight gain } \\
\% \text { pre-breeding weight gain } \\
\text { Total food consumption (grams) } \\
\text { Caloric intake (kcal) } \\
\text { Pre-breeding feed efficiency }\end{array}$ & $\begin{array}{c}63.5 \pm 6.2^{\mathrm{ab}} \\
43.9 \pm 6.7^{\mathrm{ab}} \\
366.0 \pm 14.0^{a} \\
1445.1 \pm 55.3^{\mathrm{a}} \\
17.4 \pm 1.8^{\mathrm{a}}\end{array}$ & $\begin{array}{c}71.5 \pm 12.7^{\mathrm{a}} \\
44.9 \pm 6.8^{\mathrm{a}} \\
409.0 \pm 38.0^{\mathrm{b}} \\
1614.9 \pm 150.6^{\mathrm{b}} \\
17.4 \pm 2.3^{\mathrm{a}} \\
\end{array}$ & $\begin{array}{c}54.0 \pm 5.6^{b} \\
34.6 \pm 3.5^{b} \\
432.8 \pm 12.7^{b} \\
1903.9 \pm 56.3^{c} \\
12.4 \pm 1.2^{b}\end{array}$ & $\begin{array}{c}0.020 \\
0.023 \\
0.002 \\
<0.001 \\
<0.001 \\
\end{array}$ \\
\hline
\end{tabular}

(wt. gained/food consumed) $\times 100$

${ }_{2 b . c}$ Superscripts across a line with the same letter are not significantly different $(p>0.050)$.

$536.0 \pm 45.6 \mathrm{~g}$. The same pattern is seen in the caloric intake $(\mathrm{p}<0.001)$. Control rats consumed 2.811.6 $\pm 74.9 \mathrm{kcal}$. while the KSC-Paste and KSC-Paste + Water consumed $2.086 .7 \pm 175.8$ and $2.117 .9 \pm 180.0 \mathrm{kcal}$. respectively. over the 24 day period. As a result of this. the feed efficiencies were significantly higher at $27.5 \pm 3.5 \%$ for the KSCPaste. $26.9 \pm 2.5 \%$ for the KSC-Paste + Water. and $21.6 \pm 1.1 \%$ for the Control group $(p<0.005)$.

Food consumption values for the $F_{1}$ generation females (Table 10) were significantly different in all values. The mean body weights on day one were not 
significantly different. The weight gains differed between the KSC-Paste + Water (71.5 \pm $12.7 \mathrm{~g})$ and Control $(54.0 \pm 5.6 \mathrm{~g})$ groups. while the KSC-Paste diet (65.5 $\pm 6.2 \mathrm{~g})$ group was not significantly different compared to the other two diets. The KSC-Paste + Water group gained significantly more weight $(p<0.05)$ as a percent at $44.9 \pm 6.8 \%$ compared to the Control gaining $34.6 \pm 3.5 \%$. The KSC-Paste group was not different from either group at $43.9 \pm 6.7 \%$. Total food consumption values differ between the KSC-Paste + Water and Control groups compared to the KSC-Paste group $(p<0.005)$. The Control rats ate $432.8 \pm 12.7 \mathrm{~g}$ and the KSC-Paste + Water consumed $409.0 \pm 38.0 \mathrm{~g}$ of diet compared to the KSC-Paste group eating the least amount at $366.0 \pm 14.0 \mathrm{~g}$ of diet. Caloric intake was significantly different among all groups $(\mathrm{p}<0.001)$. The KSC-Paste rats consumed $1.445 .1 \pm 55.3 \mathrm{kcal}$. the KSC-Paste + Water $1.614 .9 \pm 150.6 \mathrm{kcal}$. and the Control 1.903 .9 $\pm 56.3 \mathrm{kcal}$. Female feeding efficiency between the two KSC-25 groups differed significantly $(\mathrm{p}<0.001)$ from the Control group. with the KSC-Paste group resulting in $17.4 \pm 1.8 \%$ and the KSC-Paste + Water group in $17.4 \pm 2.3 \%$ compared to the Control group having $12.4 \pm 1.2 \%$.

Water consumption for both males and females (Figure 2) was significantly different over the 24 day pre-breeding period. The male water consumption of the KSCPaste + Water was significantly higher $(\mathrm{p}<0.005)$ at $1.245 .5 \pm 188.5 \mathrm{ml}$ compared to the KSC-Paste and Control groups. drinking 1.021.7 $\pm 90.0 \mathrm{ml}$ and $905.4 \pm 59.5 \mathrm{ml}$. respectively. There was a significant difference $(p<0.01)$ in water consumption between females in the KSC-Paste and KSC-Paste + Water groups. The KSC-Paste groups drank 
less water $(714.7 \pm 34.3 \mathrm{ml})$ than the KSC-Paste + Water $(1.050 .8 \pm 219.2)$ while the

Control group was not significantly different compared to either the KSC-Paste or KSCPaste + Water groups.

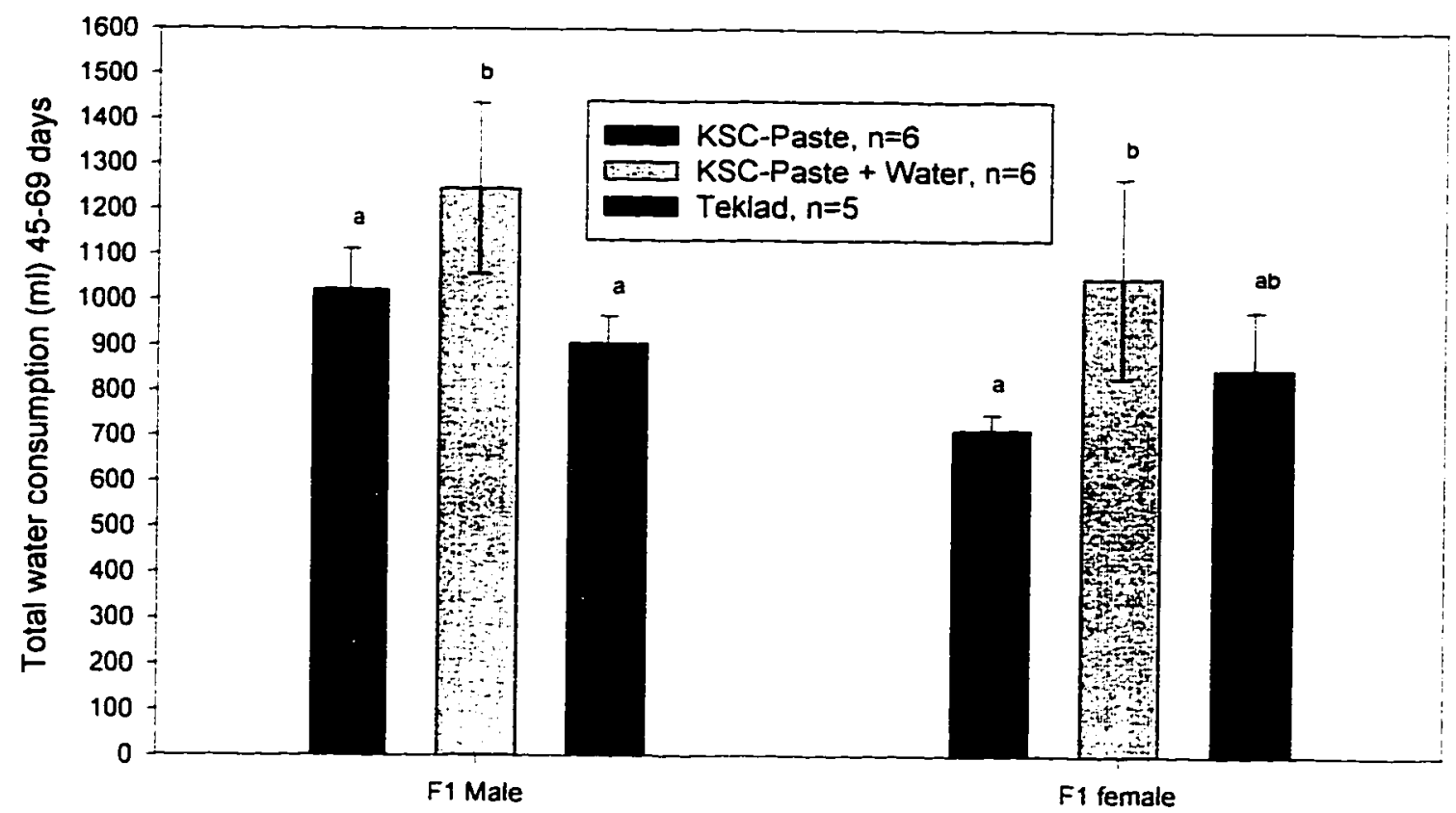

Figure 2. Mean total water consumption and standard deviation over 24 day pre-breeding period for $F_{1}$ generation males and females. $p<0.005$ for males and $p<0.01$ for females.

${ }^{a b}$ Superscripts across a line with the same letter are not significantly different $(p>0.05)$.

Estrus cycle activity for the $F_{1}$ generation is found in Table 11 . The results were similar to the parent generation cycling but were not significant $\left(\chi^{2}=1.502\right.$. and $\left.p>0.25\right)$.

Table 11. Estrus cycle activity of $F_{1}$ generation for first mating $\left(\chi^{2}=1.502\right.$. and $\left.p>0.25\right)$.

\begin{tabular}{|l|c|c|c|}
\hline Group & KSC-Paste & KSC-Paste + Water & Control \\
\hline \hline $\mathrm{n}=$ & 6 & 6 & 5 \\
\hline Females cycling & 5 & 5 & 5 \\
\hline
\end{tabular}

The $F_{1}$ breeding results for the first mating are shown in Table 12. Five of the six females produced litters in the KSC-Paste group (four out of six in the first attempt and one out of two in the re-mating attempt) while the KSC-Paste + Water group had a large 
reduction in births with only two out of six matings (none of the four females became pregnant in the re-mating attempt). The Control group had $100 \%$ successful births from the matings. Both the KSC-Paste and Control groups had births from matings in which no sperm plug was detected. There were no apparent reabsorptions in any groups. The instance of sperm plugs being detected and no pregnancy resulting happened in both

Table 12. Breeding results for $F_{1}$ generation (first mating) female rats in each diet group ( $\chi^{2}=7.552$. and $\mathrm{p}<0.025$ for number of births).

\begin{tabular}{|l|c|c|c|}
\hline & KSC-Paste & KSC-Paste - Water & Control \\
\hline \hline$n=$ & 6 & 6 & 5 \\
\hline Births & $5^{*}$ & $2^{*}$ & 5 \\
\hline Births w/out sperm plug observed ${ }^{2}$ & 2 & 0 & 2 \\
\hline Females with total reabsorptions & 0 & 0 & 0 \\
\hline Females w/sperm plug +. not pregnant & 1 & 1 & 0 \\
\hline Litters with dead pups/pups eaten & 2 & 2 & 3 \\
\hline
\end{tabular}

${ }^{3}$ Number of females that gave birth without detection of sperm plug.

${ }^{b}$ Number of females that were pregnant based on weight gain but did not give birth.

- Number of sperm plug positive females that did not become pregnant.

* Females that did not conceive the first mating were re-mated.

the KSC-Paste and KSC-Paste + Water diet groups. All groups were seen with dead pups in cages shortly after birth and/or evidence of pups being consumed by the mothers. The KSC-Paste and KSC-Paste + Water groups had 2 instances of pup cannibalization observed each and the Control group had 3 instances observed.

The number of pups per birth was not significantly different between the three diet groups (Table 13). The mean birth number for the KSC-Paste group was $7.0 \pm 6.9$ pups per mother. the KSC-Paste + Water group had $9.5 \pm 2.1$ pups per mother. and the Control group had $9.0 \pm 3.8$ pups per mother. All three groups. KSC-Paste. KSC-Paste + Water. and Control. had significantly different $(p<0.001)$ mean pup weights at culling (day 6 ) with weights of $12.4 \pm 1.9,10.8 \pm 1.5$. and $14.2 \pm 1.3$ g. respectively. 
Table 13. Mean number and culling weight of pups born to $F_{1}$ generation first mating.

\begin{tabular}{|l|c|c|c|c|}
\hline & $\begin{array}{c}\text { KSC-Paste } \\
\mathrm{n}=4^{*}\end{array}$ & $\begin{array}{c}\text { KSC-Paste + Water } \\
\mathrm{n}=2\end{array}$ & $\begin{array}{c}\text { Control } \\
\mathrm{n}=5\end{array}$ & $\mathrm{p}$ \\
\hline Mean \# pups & $7.0 \pm 6.9$ & $9.5 \pm 2.1$ & $9.0 \pm 3.8$ & 0.788 \\
\hline Mean 6 day weight $(\mathrm{g})$ & $12.4 \pm 1.9^{\mathrm{a}}$ & $10.8 \pm 1.5^{\mathrm{b}}$ & $14.2+1.3^{\mathrm{c}}$ & $<0.001$ \\
\hline
\end{tabular}

a.b.c Superscripts across a line with the same letter are not significantly different $(p>0.05)$.

- One female had 2 pups born that died within 2 days.

The second mating attempt for the $F_{1}$ generation had the same estrus cycling results as the first mating as shown in Table 14. The KSC-Paste and KSC-Paste + Water had one female each that was not cycling. which was not significantly different from the Control females $\left(\chi^{2}=1.502\right.$ and $\left.p>0.25\right)$.

Table 14. Estrus cycle activity of $F_{1}$ generation for second mating $\left(\chi^{2}=1.502\right.$ and $\left.p>0.25\right)$

\begin{tabular}{|l|c|c|c|}
\hline Group & KSC-Paste & KSC-Paste + Water & Control \\
\hline \hline $\mathrm{n}=$ & 6 & 6 & 5 \\
\hline Females cycling & 5 & 5 & 5 \\
\hline
\end{tabular}

The second mating resulted in decreased fertility for all groups. A drastic reduction in full term pregnancies was seen in both KSC-25 diet groups (Table 15). Of the five rats in the KSC-Paste group only two litters were produced (none of the four females produced litters in the re-mating attempt). A greater reduction was seen in the KSC-Paste + Water group resulting in only one litter of pups (the re-mating of the other female did not result in a litter). The Control group had one unsuccessful mating. Normal births were seen in both the KSC-Paste and Control females. Both the KSCPaste and KSC-Paste + Water groups had animals with dramatic weight gains and appeared to be pregnant. but did not deliver. The KSC-Paste and Control groups were both observed to have eaten pups and the KSC-Paste group had dead pups found in the cages. 
Table 15. Breeding results for $F_{1}$ generation (second mating) female rats in each diet group $\left(\chi^{2}=4.986\right.$. and $\mathrm{p}>0.05$ for number of births).

\begin{tabular}{|l|c|c|c|}
\hline & KSC-Paste & KSC-Paste + Water & Control \\
\hline \hline $\mathrm{n}=$ & 6 & 6 & 5 \\
\hline Births & $2^{*}$ & $1^{*}$ & $4^{*}$ \\
\hline Births wiout sperm plug observed ${ }^{2}$ & 1 & 0 & 1 \\
\hline Females with total reabsorptions $^{6}$ & 1 & 1 & 0 \\
\hline Females w/sperm plug +. not pregnant & 2 & 1 & 0 \\
\hline Litters with dead pups/pups eaten & 3 & 0 & 1 \\
\hline
\end{tabular}

Number of females that gave birth without detection of sperm plug.

${ }^{b}$ Number of females that were pregnant based on weight gain but did not give birh.

${ }^{c}$ Number of sperm plug positive females that did not become pregnant.

* Females that did not conceive in the first attempt of the second breeding period were re-mated.

The pups born to the reduced litters were not born in significantly different numbers. as can be seen in Table 16. Although producing only one litter. the KSC-Paste + Water female gave birth to 12 pups. There was a broad range of pup numbers in the KSC-Paste group. but the mean ( $10.5 \pm 7.8$ pups) was similar to the other groups. The

Table 16. Mean number and culling weight of pups born to $F_{1}$ generation second mating .

\begin{tabular}{|l|c|c|c|c|}
\hline & $\begin{array}{c}\text { KSC-Paste } \\
n=2\end{array}$ & $\begin{array}{c}\text { KSC-Paste - Water } \\
n=1\end{array}$ & $\begin{array}{c}\text { Control } \\
n=4\end{array}$ & $p$ \\
\hline Mean \# pups & $10.5 \pm 7.8$ & 12 & $13.0 \pm 2.2$ & 0.933 \\
\hline Mean 6 day weight & $13.4 \pm 1.4^{\mathrm{a}}$ & $10.2 \pm 1.6^{\mathrm{b}}$ & $13.7 \pm 1.8^{\mathrm{a}}$ & $<0.001$ \\
\hline
\end{tabular}

${ }^{2, b}$ Superscripts across a line with the same letter are not significantly different $(p>0.05)$.

weights of the pups were significantly lighter $(10.2 \pm 1.6$ pups with $p<0.001)$ than the KSC-Paste (13.4 \pm 1.4$)$ and Control (13.7 \pm 1.8$)$ pups. Removal of the runt outlier pup did not change the $\mathrm{p}$ value.

Necropsy data for the male $F_{1}$ generation are presented in Table 17. Organs are presented as percent total body weight and mean blood values are included as well. There was not a significant difference between groups for the adrenals. heart. and thymus. Total 
body weights were significantiy smaller $(p<0.01)$ in the Control group with a mean body weight of $548.0 \pm 40.3 \mathrm{~g}$ compared to the KSC-25-Paste and KSC-25-Paste + Water

Table 17. Male $F_{1}$ generation organ weights as percentage of total body weight and mean blood values with standard deviations.

\begin{tabular}{|c|c|c|c|c|}
\hline Mean Organ Wt. & $\begin{array}{c}\begin{array}{c}\text { KSC-Paste } \\
\mathrm{n}=6\end{array} \\
\end{array}$ & $\begin{array}{c}\text { KSC-Paste - Water } \\
n=6\end{array}$ & $\begin{array}{c}\begin{array}{c}\text { Control } \\
n=5\end{array} \\
\end{array}$ & $\mathrm{p}$ \\
\hline Total Body Weight & $645.7 \pm 70.0^{\mathrm{a}}$ & $672.8 \pm 46.2^{\mathrm{a}}$ & $548.0 \pm 40.3^{\mathrm{b}}$ & 0.006 \\
\hline Eviscerated carcass & $50.7 \pm 3.6^{2}$ & $49.1 \pm 3.0^{2}$ & $56.5 \pm 1.7^{b}$ & 0.003 \\
\hline Skin & $28.4 \pm 3.6^{3}$ & $30.4 \pm 2.8^{3}$ & $21.5 \pm 1.3^{b}$ & $<0.001$ \\
\hline Adrenals & $0.008 \pm 0.003$ & $0.008 \pm 0.003$ & $0.010 \pm 0.004$ & 0.726 \\
\hline Heart & $0.27 \pm 0.03$ & $0.25 \pm 0.01$ & $0.28 \pm 0.02$ & 0.078 \\
\hline Thymus & $0.044 \pm 0.014$ & $0.037 \pm 0.013$ & $0.034 \pm 0.006$ & 0.473 \\
\hline Spleen & $0.14 \pm 0.01^{a}$ & $0.14 \pm 0.01^{\mathrm{a}}$ & $0.18 \pm 0.03^{b}$ & 0.002 \\
\hline Kidney & $0.59 \pm 0.05^{\circ}$ & $0.61 \pm 0.04^{2}$ & $0.76 \pm 0.09^{b}$ & $<0.001$ \\
\hline Testes & $0.51 \pm 0.17^{a}$ & $0.54 \pm 0.04^{2}$ & $0.72 \pm 0.03^{b}$ & $0.006^{*}$ \\
\hline \multicolumn{5}{|l|}{ Mean blood values* } \\
\hline Hematocrit & $48.8 \pm 3.0$ & $48.7 \pm 1.2$ & $46.0 \pm 3.2$ & 0.173 \\
\hline Hemoglobin & $17.5 \pm 0.9$ & $16.9 \pm 0.8$ & $17.9 \pm 1.0$ & 0.219 \\
\hline $\mathrm{RBC}$ & $8.72 \pm 0.94$ & $8.96 \pm 0.89$ & $8.90 \pm 1.38$ & 0.924 \\
\hline WBC & $11.65 \pm 2.30$ & $11.90 \pm 1.75$ & $9.35 \pm 2.02$ & 0.117 \\
\hline Neutrophils & $38.3 \pm 38.4$ & $12.8 \pm 3.9$ & $19.0 \pm 6.3$ & 0.277 \\
\hline Ljimpocytes & $61.2 \pm 37.7$ & $86.3 \pm 4.0$ & $79.6 \pm 6.3$ & $0.196^{*}$ \\
\hline Eosinophils & $0.83 \pm 1.17$ & $1.50 \pm 1.05$ & $1.60 \pm 1.52$ & 0.538 \\
\hline Monocytes & 0 & 0 & 0 & \\
\hline Basophils & 0 & 0 & 0 & \\
\hline Bands & 0 & 0 & 0 & \\
\hline
\end{tabular}

${ }^{2 b}$ Superscripts across a line with the same letter are not significantly different $(p>0.05)$

* Units for hematocrit as \%, hemoglobin as g/dl. red blood cell count as (KBC) $\times 10^{6} / \mathrm{mm}^{3}$. white blood cell count as (WBC) $\times 10^{3} / \mathrm{mm}^{3}$. Differential white blood cells expressed as percent.

* Indicates ANOVA on ranks (Kruskal-Wallis).

groups weighing $645.7 \pm 70.0 \mathrm{~g}$ and $672.8 \pm 46.2 \mathrm{~g}$. respectively. The Control group eviscerated carcass percentage of total body weight was significantly larger $(p<0.005)$ than the KSC-25-Paste and KSC-25-Paste + Water groups ( $56.5 \pm 1.7 \%$ compared to 50.7 $\pm 3.6 \%$ and $49.1 \pm 3.0 \%$. respectively). Skin percentage of total body weight for the KSC-25-Paste group was $28.4 \pm 3.6 \%$ and the KSC-25-Paste + Water group was $30.4 \pm$ 
$2.8 \%$. which were both significantly higher $(\mathrm{p}<0.001)$ than the Control group at $21.5 \pm$ 1.3\%. Much of this difference in weight in the KSC-25 groups was due to excessive fat accumulation which associated with the skin. Spleen percentages for both the KSC-25 groups were significantly smaller $(p<0.005)$ at $0.14 \pm 0.01 \%$ compared to the Control group at $0.18 \pm 0.03 \%$. Kidney percentages KSC-25-Paste and KSC-25-Paste + Water were both significantly smaller $(p<0.001)$ at $0.59 \pm 0.05$ and $0.54 \pm 0.04$. than the Control group at $0.76 \pm 0.03 \%$. The testes in both the KSC-25 diets were significantly smaller $(p<0.01)$ at $0.51 \pm 0.17 \%$ for the KSC-Paste and $0.54 \pm 0.04 \%$ for the KSC-Paste + Water compared to the Control testes at $0.72 \pm 0.03 \%$. There were no significant differences in any of the blood parameters.

The comparison of $F_{1}$ male organs as a percentage of carcass weight (not shown) results in the KSC-25 groups having significantly smaller testes $(\mathrm{p}<0.01)$ and significantly larger skin percentages $(\mathrm{p}<0.005)$. All other organs were similar in percentage of carcass weight.

Female organs as a percent of carcass weight and blood mean work are presented in Table 18. The KSC-25-Paste + Water total body weight $(449.5 \pm 75.1 \mathrm{~g})$ was significantly different $(p<0.05)$ from the Control group $(347.8 \pm 13.5 \mathrm{~g})$. while the KSC25-Paste group was not significantly different from either group $(363.5 \pm 33.5 \mathrm{~g})$. The KSC-25-Paste eviscerated carcass as percentage of total body weight was significantly larger $(p<0.05)$ at $56.0 \pm 3.3 \%$ than the KSC-25-Paste + Water group percentage of 48.0 \pm 4.0 (the Control group was not significant to either KSC-25 group 
Table 18. Female $F_{1}$ generation organ weights as percentage of total body weight and mean blood values
with standard deviations. Mean Organ $W_{t}$.

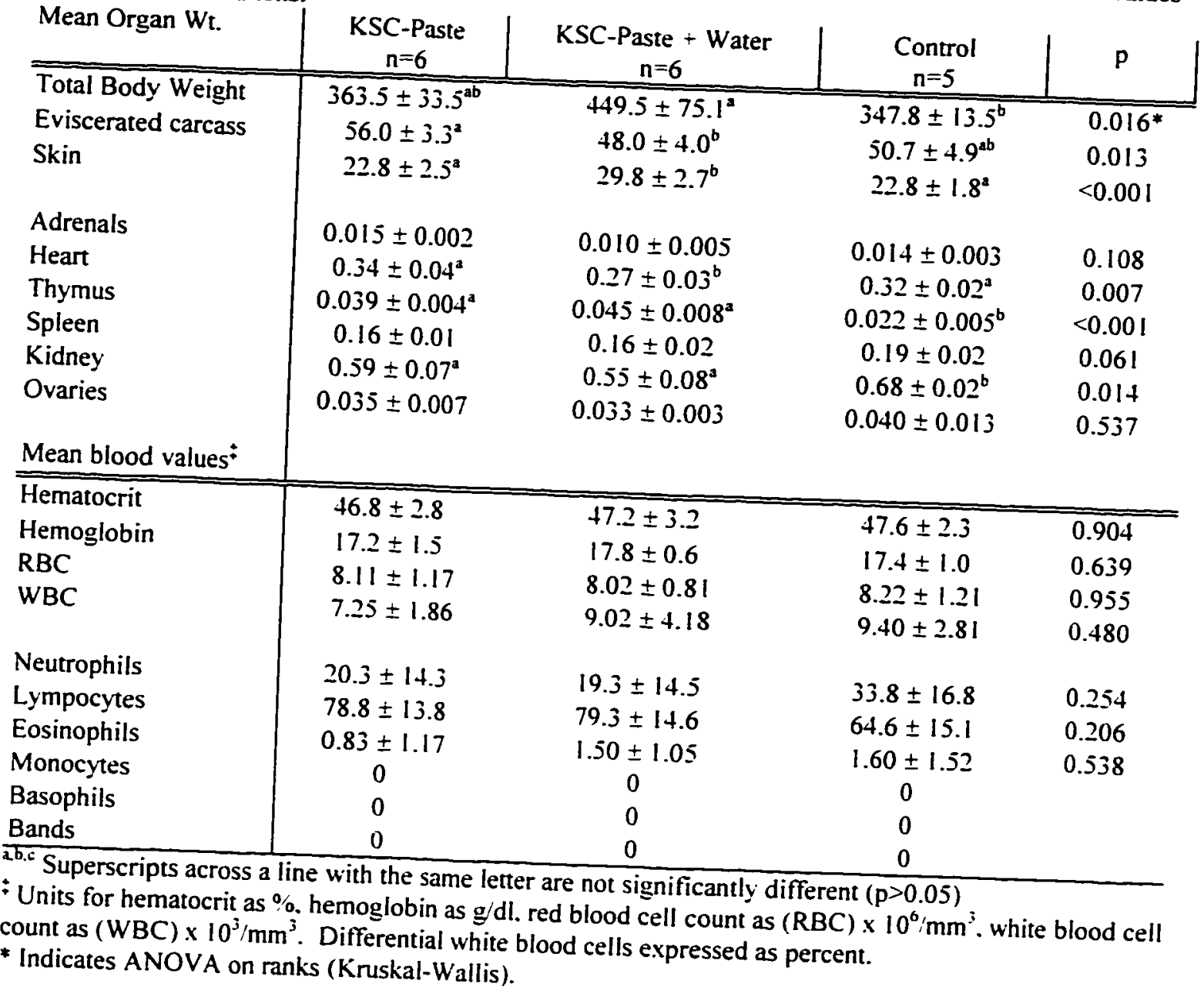

with a total body weight percentage of $50.76 \pm 4.9$ ). The skin mean percentage for the KSC-25-Paste + Water $(29.8 \pm 2.7 \%)$ were significantly larger $(\mathrm{p}<0.001)$ than both the KSC-25-Paste and Control groups ( $22.8 \pm 2.5 \%$ and $22.8 \pm 1.8$. respectively). The adrenals'. spleen. and ovaries ${ }^{\circ}$ percentage of total body weight were not significantly different from each other. The hearts of the KSC-25-Paste + Water group were $0.27 \pm$ $0.03 \%$ of the total body weight which were significantly smaller $(p<0.01)$ than the percentages of the KSC-25-Paste group $(0.34 \pm 0.04 \%)$ and the Control group $(0.32 \pm$ 
0.02\%). Thymus percentages for both the KSC-25-Paste and KSC-25-Paste + Water groups were significantly larger than the Control group $(p<0.001)$. The KSC-25-Paste group thymus was $0.039 \pm 0.004 \%$ and the KSC-25-Paste + Water group was $0.045 \pm$ $0.008 \%$ compared to the Control group $0.022 \pm 0.005 \%$. Kidney percentage of total body weight for the Control group was significantly larger at $0.68 \pm 0.02 \%$ than both the KSC25-Paste group percentage of $0.59 \pm 0.07$ and the KSC-25-Paste + Water percentage of $0.55 \pm 0.08(\mathrm{p}<0.05)$. None of the blood parameters were significantly different for any of the $F_{1}$ female groups.

Female $F_{1}$ organs analyzed as a percentage of carcass weight (not shown) result in larger skins in the KSC-25-Paste + Water group $(\mathrm{p}<0.005)$. The thymus percentages are significantly different between all groups $(p<0.001)$ with the Control group the smallest and the KSC-25-Paste + Water group the largest. KSC-25-Paste Spleen percentages were significantly smaller than the Controls (KSC-25-Paste + Water were not significant from either group). The kidneys for the KSC-25 groups were smaller than the Control groups $(p<0.001)$. Adrenals. heart. and ovaries were not significantly different between groups.

\section{Discussion}

The KSC- 25 paste diet (containing $66 \%$ water) has been shown to have adequate nutrient levels and be an adequate diet for growing rats (8.9). The present study looked into the long term effects of the KSC-25 diet on the breeding efficiency of rats. 
The KSC-Paste and KSC-Paste + Water groups in both the parent and $F_{1}$ generation had higher feed efficiencies than the Control groups (Tables 2 and 10). One contribution to this is the lower dry food equivalent (the percentage of the paste diet that is the purified solid components in grams) of KSC-25 consumed by the test groups. With the exception of the females from the $F_{1}$ generation. all KSC-25 groups (males and females) had similar weight gains during the pre-breeding period. yet consumed less food. This resulted in the KSC-25 groups having higher feed efficiencies. Since the KSC-25 is a purified diet. all of the components in the diet are of known proportion and contribute to the caloric value of the diet. Standard rodent chows consist of cereals and meals that are not fully digestible. and that may, thus. contribute to both the weight of the food and the caloric value of the chow. Both of these may contribute to the difference in the feed efficiencies and kcal consumed over those periods. Thus. the chow rats may have to eat more food mass to get the desired kcal requirement from the diet. Since the KSC-25 diet is purified and theoretically in a form that is "utilizable". the rats on this diet consume fewer calories.

The preparation of the diet with $66 \%$ water was the original formulation used by Battles $(7,8)$ and was based on the idea that lactating dams would require extra water. To test this assumption (and as a way to quantitatively measure the potential increased needs of water above the percentage already present in the diet). supplemental water was provided to one of the KSC-25 groups. Water consumption by the KSC-Paste + Water males and females of the parent and the males of the $F_{1}$ generation was significantly 
greater due to the added availability of ad libitum water than the Control rats. Some rats in the KSC-Paste + Water groups would go many days without drinking any water while some would consistently drink water daily. In an earlier study serum protein levels. serum electrolyte levels. urine specific gravity. and hematocrit indicated that the KSC-25 diet without supplemental water provided adequate amounts of water (8). Based on these data. the drinking of supplemental water by the KSC-Paste + Water group was not necessarily driven by thirst. Results of the breeding (discussed below) indicate that the water content of the diet is adequate for the needs of pregnant and nursing dams.

Estrous cycling between the matings was not different among the groups. and results of the matings in the parent generation breeding is not dramatically different. Four of the six females in both the KSC-Paste and KSC-Paste + Water groups needed to be remated. however. and three then did become pregnant from proven male breeders. The $F_{1}$ matings showed decreases in the number of litters produced and lower pup weights in those litters for the KSC-25-Paste + Water group. In addition to decreased numbers of litters, the KSC-Paste and KSC-Paste + Water groups had more pup mortality. Males were not examined for sterility and factors such as low sperm count cannot be ruled out. Since the testes for the $F_{1}$ males were smaller as a percentage of total body weight (and both male parent and $F_{1}$ males had smaller testes as percentage of carcass weight). this could be a possible contributor to the decreased fertility. This is a hypothesis to be tested in the future. Female reabsorptions not detected by weight gain could not be confirmed 
by uterine dissection at day 19 or 20 of gestation because the rats were needed for second or third mating attempts.

The difference in water consumption between the KSC-Paste and KSC-Paste + Water groups did not indicate that the supplemental water was needed. In the parent generation. both males and females in the KSC-25 groups drank more water than the Control group (Figure 1). In the $F_{1}$ generation. the KSC-25-Paste + Water males drank more water than the KSC-25-Paste and Control groups and the KSC-25-Paste + Water females drank more than the KSC-25-Paste females. The Control group water consumption was not different from the KSC-25 groups (Figure 2). There was a correlation between the increased water consumption and decreased reproductive efficiency in the KSC-Paste + Water group in the $F_{1}$ generation. but whether the increased water consumption is the cause of the decreased reproductive efficiency is an issue that needs to be further investigated.

Analysis of the organs result in a trend seen in both generations: all KSC-25 groups for both sexes (except the $F_{1}$ males) have significantly larger eviscerated carcass weights. Other than total body weight. there was no apparent trend in which any organ was consistently different among generations or sexes. Total body weights are significantly different in both of the KSC-25 diet males from the $\mathrm{F}_{1}$ generation (KSC-25Paste + Water females in the $F_{1}$ generation are also larger than the Control group). Part of the reason for the larger body weights in the KSC-25 groups from the $F_{1}$ male generation is due to older animal age. The $F_{1}$ generation animals were older because of 
the failed mating attempts which resulted in multiple re-matings and consequently older animals. Heart percentages in the female parent generation were not significantly different. but the heart percentages in the $F_{1}$ generation were significantly different. This appears to be an isolated incident and probably due to small sample size since it was not seen in either of the male generations. Differences in the thymus percentage of carcass weight for females in all KSC-25 groups in both generations are difficult to explain. Because the thymus typically decreases in size as an animal ages. the difference may be due to differences in individual thymus atrophy rates.

The hematocrit and hemoglobin of the KSC-Paste and KSC-Paste + Water females in the parent generation were significantly higher than the controls. Based on published hematocrit values of $46.0 \pm 1.5 \%$ for $4-6$ month old female Sprague-Dawley rats. the KSC-Paste and KSC-Paste + Water groups were 9.8 and $7.2 \%$ higher (13). Although the hemoglobin values for the female KSC-25 groups were significantly different from the Control group. the values for the Control group were lower than published values $(15.2 \pm 0.7 \mathrm{~g} / \mathrm{dl})$ for females that age (13).

Females of the KSC-Paste + Water and Control groups in the parent generation had significantly higher neutrophil counts compared to the KSC-Paste group which was normal in respect to its count. This neutrophil increase may have been caused by an increase in some bacterial population in some members of those diet groups. This high neutrophil count would influence the proportion of lymphocytes resulting in the decreased number counted in the blood (or is a result of a decrease in lymphocytes). 
The KSC-25 diet containing $66 \%$ water is adequate for short term growth and development, but relatively poor support of long term multigenerational breeding requirements of rats. Some characteristic of the KSC-25 diet formula (unknown at this time) results in a decrease in fertility of rats maintained on it for extended periods. Future studies should be performed to determine if there are bioavailability problems associated with some of the diet formulation components. 


\section{References}

1. Rutten. A. A. J. J. L.. and A. P. De Groot. 1992. Comparisons of cereal-based diet with purified diet by short-term feeding studies in rats. mice and hamsters, with emphasis on toxicity characteristics. Food and Chemical Toxicology. 30(7): 601-610.

2. Bieri, J. G. 1977. Report of the American Institute of Nutrition ad hoc committee on standards for nutritional studies. J. Nutr. 107: 1340-1348.

3. Bieri. J. G. 1980. Second report of the ad hoc committee on standards for nutritional studies. J. Nutr. 110: 1726.

4. Pace. N.. D. F. Rahlman. A. H. Smith. and G. C. Pitts. 1981. Effects of the Cosmos 1129 Soviet paste diet on body composition in the growing rat. Environmental Physiology Laboratory report. University of California. Berkeley. CA.

5. Reeves, P. G.. F. H. Nielsen. and G. C. Fahey. Jr. 1993. AIN-93 purified diets for laboratory rodents: Final report of the American Institute of Nutrition ad hoc writing committee on the reformulation of the AIN-76A diet. J. Nutr. 123: 1939-1951.

6. Reeves. P. G.. K. L. Rossow. and J. Lindlauf. 1993. Development and testing of the AIN-93 purified diets for rodents: results on growth. kidney calcification and bone mineralization in rats and mice. J. Nutr. 123: 1923-1931.

7. Battles. A. H.. J. T. Knapka. L. Lewis. M. T. Lang. and D. J. Gruendel. 1991. Highmoisture diet for laboratory rats: I. Nutrient analysis. growth. organ weights. Lab Anim. Sci.. 41(3):237-241.

8. Battles. A. H.. J. T. Knapka. B. R. Stevens, L. Lewis, M. T. Lang. and D. J. Gruendel. 1991. High-moisture diet for laboratory rats: Complete blood counts. serum biochemical values, and intestinal enzyme activity. Lab Anim. Sci.. 41(3): 242-245.

9. Gossett. J. D.. V. E. Strength. and D. C. Holley. Oct. 1995. Assessment of a Chew Device for Use with Paste Diets. Poster presentation at American Society of Gravitational and Space Biology meeting.

10. Norris, David O.. Vertebrate Endocrinology. $3^{\text {rd }}$. ed.. Academic Press. San Diego. 1997.

11. Harkness. John E.. and Joseph E. Wagner. The Biology and Medicine of Rabbits and Rodents. $3^{\text {rd }}$ ed.. Lea and Febiger. Philadelphia. 1989. 
12. Zar. Jerrold H.. Biostatistical Analysis. $3^{\text {rd }}$ ed.. Prentice Hall. New Jersey. 1996.

13. Jain. Nemi C.. Schalm's Veterinary Hematology, 4th ed.. Lea and Febiger. Philadelphia. 1986. 